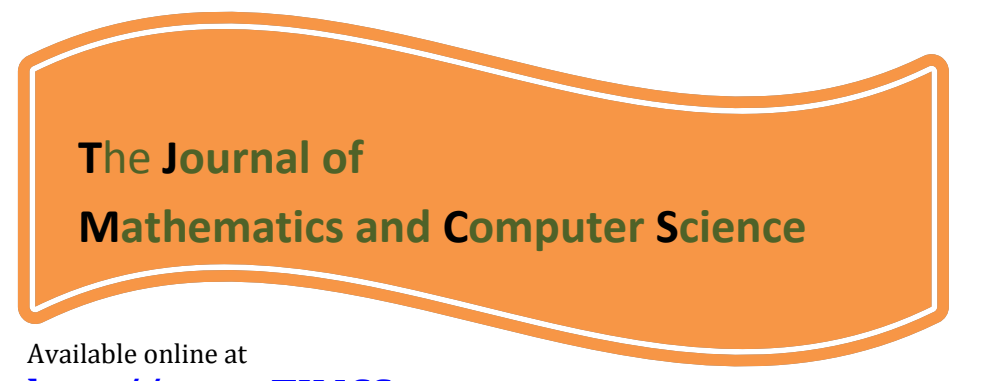

\title{
http://www.TIMCS.com
}

The Journal of Mathematics and Computer Science Vol .5 No.4 (2012) 271-279

\section{Mathematical Modeling of Thermosyphon Heat Exchanger for Energy Saving}

\author{
Mohammad Reza Sarmasti Emami \\ Iran University of Science and Technology, Behshahr, Iran \\ m_r_emami@iust.ac.ir
}

Received: February 2012, Revised: November 2012

Online Publication: December 2012

\begin{abstract}
Waste heat recovery is very important, because not only it reduces the expenditure of heat generation, but also it is of high priority in environmental consideration, such as reduction in greenhouse gases. One of the devices is used in waste heat recovery is thermosyphon heat exchanger (THE). In this paper, theoretical research has been carried out to investigate the thermal performance of an air to air thermosyphon heat exchanger. This purpose is done by solving simultaneous principles equations. It was found that with implementation of targeted subsides plan in Islamic Republic of Iran, saving in gas oil consumption is very considerable by using this device.
\end{abstract}

Keywords: Mathematical Modeling; Thermosyphon Heat Exchanger; Energy Saving

\section{Introduction}

The thermosyphon heat exchanger is one of the attractive devices used in waste heat recovery because of its high effectiveness in heat transfer and other special features [1] Various attempts to predict the performance of thermosyphon heat exchanger (THE) have been proposed [2-3] Pollution depends on energy consumption. Today the world daily oil consumption is 76 million barrels. Despite the well-known consequences of fossil fuel combustion on the environment, this is expected to increase to 123 million barrels per day by the year 2025 [4] A heat pipe consist of tube with a small amount of working fluid, which is in equilibrium with its own vapor sealed inside container (pipe wall and end caps), is a very effective heat transfer device, which allows a very high rate of heat transfer in the process of evaporation and condensation. In addition, heat pipe simple, cheap, and easy to construct using small end-to-end temperature drops. It has an extremely wide temperature application 
range $(4-3000 \mathrm{~K})$, and is an effective device that requires no external driving force other than the temperature differences. THEs have been used in many ways, in boilers, furnaces and dryers, especially for energy recovery industry. Counter flow heat exchangers using thermosyphons as shown in Fig. (1) can be made without constructional difficulties.

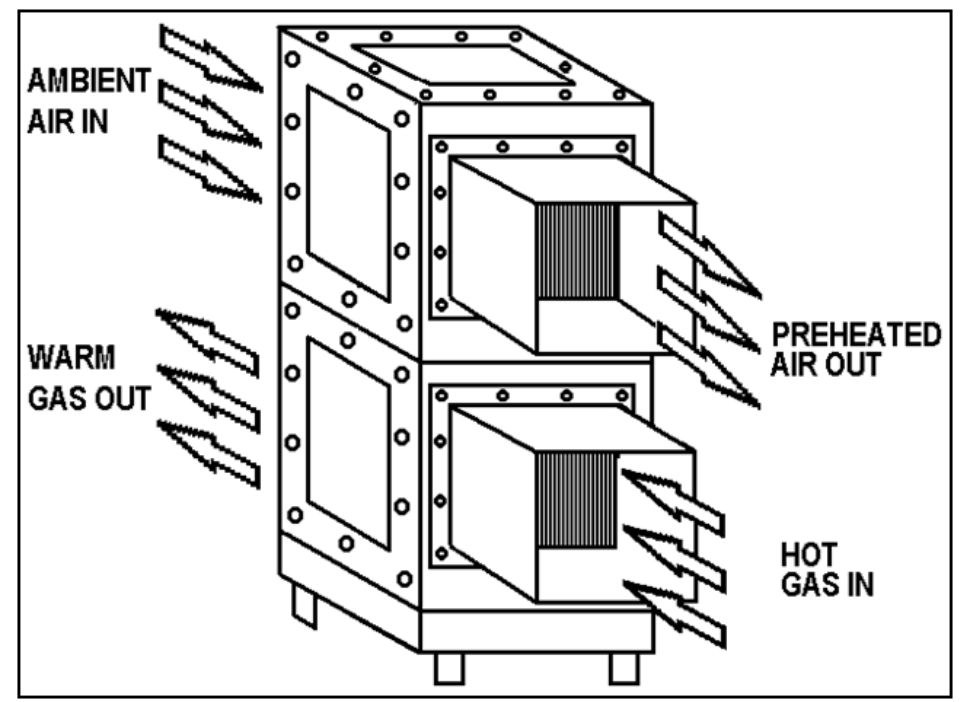

Fig. 1: Schematic of THE

\section{Mathematical model description}

The analysis of the heat transfer aspects of THE is based on the heat transfer rate equation obtained by an energy balance of the heat exchanger:

$$
Q=U . S\left(T_{h}-T_{c}\right)
$$

There are two main approaches for designing of a THE:

1. The Log-mean temperature difference model (LMTD).

2. The effectiveness-number of transfer units model ( $\varepsilon$-NTU) $[5,6]$

\section{1. $\varepsilon$-NTU Method}

The $\varepsilon$-NTU method is based on the heat exchanger effectiveness, $\varepsilon$, which is defined as the ratio of the actual heat transfer of a heat exchanger to the one that would have occurred in a heat exchanger with infinite surface. The exit temperature of the low-temperature fluid would equal the inlet temperature of the high-temperature fluid. Therefore, the effectiveness can be defined as [7]:

$$
\varepsilon=\frac{Q_{a c t}}{Q_{\max }}=\frac{C_{c}\left(T_{h, \text { in }}-T_{h, \text { out }}\right)}{C_{\text {min }}\left(T_{h, \text { in }}-T_{c, \text { in }}\right)}=\frac{C_{c}\left(T_{c, \text { out }}-T_{c, \text { in }}\right)}{C_{\text {min }}\left(T_{h, \text { in }}-T_{c, \text { in }}\right)}
$$

Applying conservation of energy, the general exponential function for a counter-flow heat changer is [8]: 


$$
\varepsilon=\frac{1-\exp \left[\frac{-\mathrm{u}_{\mathrm{t}} \mathrm{A}_{\mathrm{t}}}{\mathrm{C}_{\min }}\left(1-\frac{\mathrm{C}_{\min }}{\mathrm{C}_{\max }}\right)\right]}{1-\frac{\mathrm{C}_{\text {min }}}{\mathrm{C}_{\max }} \exp \left[\frac{-\mathrm{u}_{\mathrm{t} .} \mathrm{A}_{\mathrm{t}}}{\mathrm{C}_{\min }}\left(1-\frac{\mathrm{C}_{\text {min }}}{\mathrm{C}_{\max }}\right)\right]}
$$

The ratio of $\frac{(U s)_{t}}{C_{\min }}$ is defined as the number of transfer units:

$$
N T U=\frac{U_{t} S_{t}}{C_{\min }}
$$

The $\mathrm{C}_{\min }$ and $C_{\max }$ are the minimum heat capacity and the maximum heat capacity of fluid through the THE.

$$
\begin{aligned}
& C_{\text {min }}=\left(\dot{m} C_{p}\right)_{\text {min }} \\
& C_{\text {max }}=\left(\dot{m} C_{p}\right)_{\text {max }}
\end{aligned}
$$

And the $C_{\mathrm{e}}$ and $\mathrm{C}_{\mathrm{c}}$ are the heat capacities of the fluid streams in evaporator and condenser sections of the THE, respectively.

$$
\begin{gathered}
C_{e}=\left(\dot{m} C_{p}\right)_{e} \\
C_{c}=\left(\dot{m} C_{p}\right)_{c} \\
\frac{C_{e}}{C_{c}}=\frac{\left(\dot{m} C_{p}\right)_{e}}{\left(\dot{m} C_{p}\right)_{c}}
\end{gathered}
$$

The heat capacity ratio of high- and low-temperature fluid streams $\left(\mathrm{C}_{\mathrm{e}} / \mathrm{C}_{\mathrm{c}}\right)$ is being used to investigate thermal performance of THE. Therefore, the effectiveness can be obtained by the following correlations:

$$
\begin{gathered}
\varepsilon=\frac{\left(T_{c, \text { out }}-T_{c, \text { in }}\right)}{\left(T_{h, \text { in }}-T_{c, \text { in }}\right)}, \text { if } C_{e}<C_{c} \\
\varepsilon=\frac{C_{c}\left(T_{h, \text { in }}-T_{h, \text { out }}\right)}{C_{\min }\left(T_{h, \text { in }}-T_{c, \text { in }}\right)}, \text { if } C_{e}>C_{c}
\end{gathered}
$$

heat capacity, $\left(\frac{C_{\min }}{C_{\max }} \approx 0\right)$.

The effectiveness will be expressed as:

$$
\varepsilon=1-\exp (-N T U)
$$

The effectiveness of evaporator and condenser sections of the THE can be defined as:

$$
\begin{aligned}
\varepsilon_{e} & =1-\exp (-N T U)_{e} \\
\varepsilon_{c} & =1-\exp (-N T U)_{c}
\end{aligned}
$$


Where:

$$
N T U_{e}=\frac{U_{e} \cdot S_{e}}{C_{e}}, N T U_{c}=\frac{U_{c} \cdot S_{c}}{C_{c}}
$$

These correlations have been defined for a single row of pipes, while the effectiveness of a THE with $n$ rows of pipes is as follows:

$$
\begin{aligned}
& \epsilon_{e}=1-\left(1-\varepsilon_{e 1}\right)^{n} \\
& \epsilon_{c}=1-\left(1-\varepsilon_{c 1}\right)^{n}
\end{aligned}
$$

At least overall effectiveness of THE is obtained by the following correlations [9]:

$$
\begin{gathered}
\varepsilon_{o}=\frac{1}{\frac{1}{\varepsilon_{c_{n}}}+\frac{C_{c} / C_{e}}{\varepsilon_{e_{n}}}} \text { if } C_{e}>C_{c} \\
\varepsilon_{o}=\frac{1}{\frac{1}{\varepsilon_{e_{n}}}+\frac{C_{e} / C_{c}}{\varepsilon_{c_{n}}}} \text { if } C_{e}<C_{c}
\end{gathered}
$$

\section{2-2. Determination of the overall heat transfer coefficient}

To determine the overall heat transfer coefficient, the heat transfer can be modeled as a thermal resistance network shown in Fig 2.

$$
\begin{gathered}
\frac{1}{U S}=\frac{1}{\left(\eta_{o} h s\right)_{c}}+R_{f, c}+R_{h p}+R_{f, h}+\frac{1}{\left(\eta_{o} h s\right)_{h}} \\
\frac{1}{U_{h} S_{h}}=\frac{1}{\left(\eta_{o} h s\right)_{h}}+\frac{1}{2 \pi K_{w} L_{e}} \ln \ln \left(\frac{D_{o}}{D_{i}}\right) \\
R_{h}=\frac{1}{\left(\eta_{o} h s\right)_{h}}, R_{w, h}=\frac{1}{2 \pi K_{w} L_{e}} \ln \ln \left(\frac{D_{o}}{D_{i}}\right)
\end{gathered}
$$

In this research, it was assumed that fouling resistances due to corrosion or oxidation as well as resistances terms which occurred due to heat transfer through the liquid saturated wick are negligible. Therefore, for the condenser section, we have:

$$
\begin{aligned}
& \frac{1}{U_{c} S_{c}}=\frac{1}{\left(\eta_{o} h s\right)_{c}}+\frac{1}{2 \pi K_{w} L_{c}} \ln \ln \left(\frac{D_{o}}{D_{i}}\right) \\
& R_{c}=\frac{1}{\left(\eta_{o} h\right)_{c}}, R_{w, c}=\frac{1}{2 \pi K_{w} L_{c}} \ln \ln \left(\frac{D_{o}}{D_{i}}\right)
\end{aligned}
$$




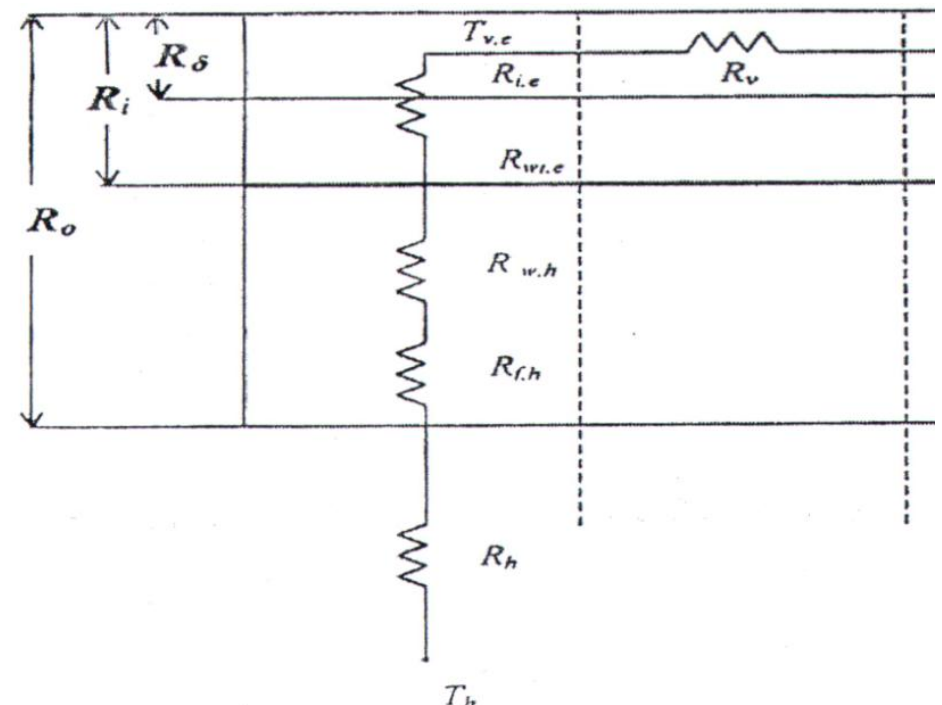

Fig 2.Thermal resistance network of a THE h:section evaporator and c: section condenser

\section{Calculation of Heat Transfer Limits}

Although heat pipes are very efficient heat transfer devices, there are various parameters that put limitation and constraints on the steady and transient operation of heat pipes. These limitations determine the maximum heat transfer rate, which must be examined for working fluid

\subsection{Sonic Limit:}

Sonic limit was computed using expressions reported by Dunn and Reay [10]:

$$
\mathrm{Q}_{c, 90}=\rho_{\mathrm{v}} \mathrm{h}_{\mathrm{fg}} \mathrm{A}_{\mathrm{v}} \sqrt{\frac{\gamma \mathrm{R}_{\mathrm{v}} \mathrm{T}_{\mathrm{v}}}{2(\gamma+1)}}
$$

\subsection{Flooding Limit:}

The flooding limit was evaluated based on a correlation based on a correlation proposed by Faghri [11]:

$$
\begin{gathered}
\mathrm{Q}_{\mathrm{c}, 90}=\mathrm{Ku}^{*} \mathrm{~h}_{\mathrm{fg}} \mathrm{A}_{\text {cross }}\left[\sigma \mathrm{g}\left(\rho_{1}-\rho_{\mathrm{v}}\right)\right]^{1 / 4} \times\left[\rho_{\mathrm{v}}^{-1 / 4}+\rho_{1}^{-1 / 4}\right]^{-2} \\
\mathrm{Ku}^{*}=\left(\frac{\rho_{1}}{\rho_{\mathrm{v}}}\right)^{0.14} \tanh ^{2}(\mathrm{Bo})^{1 / 4}
\end{gathered}
$$

\subsection{Boiling Limit}

The boiling limit was evaluated based on a correlation based on a correlation proposed by Gorbis \& savchenkov [12]:

$$
\begin{aligned}
& \frac{\mathrm{Q}_{\mathrm{c}, 90}}{\mathrm{Q}_{\mathrm{c}, \infty}}=\mathrm{C}^{2}\left[0.4+0.006 \mathrm{D}_{\mathrm{i}} \sqrt{\mathrm{g}\left(\rho_{1}-\rho_{\mathrm{v}}\right) / \sigma}\right]^{2} \\
& \mathrm{Q}_{\mathrm{c}, \infty}=0.142 \mathrm{~A}_{\mathrm{e}} \sqrt{\rho_{\mathrm{v}}}\left[\mathrm{g} \sigma\left(\rho_{1}-\rho_{\mathrm{v}}\right)\right]^{1 / 4} \\
& \mathrm{C}=0.538\left(\frac{\mathrm{D}_{\mathrm{i}}}{\mathrm{L}_{\mathrm{c}}}\right)^{0.44} \times\left(\frac{\mathrm{D}_{\mathrm{i}}}{\mathrm{L}_{\mathrm{e}}}\right)^{0.55} \psi^{0.13} \quad \psi \leq 0.35
\end{aligned}
$$


$\mathrm{C}=3.54\left(\frac{\mathrm{D}_{\mathrm{i}}}{\mathrm{L}_{\mathrm{c}}}\right)^{0.44} \times\left(\frac{\mathrm{D}_{\mathrm{i}}}{\mathrm{L}_{\mathrm{e}}}\right)^{0.55} \psi^{-0.37} \quad \psi>0.35$

\subsection{Dry-out Limit}

The dry-out limit was evaluated based on an improved Cohen and Baylay model [13]:

$$
\begin{aligned}
& \left(\frac{\mathrm{Q}_{\mathrm{c}, 90}}{\rho_{\mathrm{v}} \mathrm{h}_{\mathrm{fg}}}\right)\left[\frac{\sigma g\left(\rho_{1}-\rho_{\mathrm{v}}\right)}{\rho_{\mathrm{v}}^{2}}\right]^{-1 / 4}=\mathrm{A}_{\text {cross }}\left[\frac{\mathrm{g} \rho_{1}^{2}\left(\mathrm{D}_{\mathrm{c}} / \mathrm{D}_{\mathrm{e}}\right)}{3 \mu_{\mathrm{l}} \mathrm{L}_{\mathrm{e}} \sqrt[4]{\sigma g \rho_{\mathrm{v}}^{2}\left(\rho_{1}-\rho_{\mathrm{v}}\right)}}\right] \\
& \times\left[\frac{\mathrm{V}_{\mathrm{t}} / \pi \mathrm{D}_{\mathrm{c}}}{4 \mathrm{~L}_{\mathrm{c}} / 5+\mathrm{L}_{\mathrm{ac}}+\left(\mathrm{D}_{\mathrm{e}} / \mathrm{D}_{\mathrm{c}}\right)^{2 / 3}\left(\mathrm{~L}_{\mathrm{ae}}+3 \mathrm{~L}_{\mathrm{e}} / 4\right)}\right]^{3} \times\left[\frac{\left(\mathrm{V} \mathrm{e} / \mathrm{V}_{\mathrm{t}}\right)\left(\mathrm{V}_{\mathrm{l}} / \mathrm{V}_{\mathrm{e}}\right)-\left(\rho_{\mathrm{v}} / \rho_{\mathrm{l}}\right)}{1-\rho_{\mathrm{v}} / \rho_{1}}\right]^{3}
\end{aligned}
$$

\section{Results and Discussion}

The physical dimensions of simulated THE in heat recovery unit are shown in table (1). The effects of various parameters on thermal performance of a THE have been investigated, theoretically. The following results have obtained.

\begin{tabular}{|c|c|c|c|c|c|c|}
\hline Fin & Configuration & $\begin{array}{c}\text { Number } \\
\text { of heat } \\
\text { pipe row }\end{array}$ & $\begin{array}{c}\text { Total } \\
\text { number of } \\
\text { heat pipe }\end{array}$ & $\begin{array}{l}\text { Material } \\
\text { \&workin } \\
\text { g fluid }\end{array}$ & $\begin{array}{c}\text { Physical } \\
\text { dimension of } \\
\text { HPHE }\end{array}$ & $\begin{array}{l}\text { Physical } \\
\text { dimension } \\
\text { of each } \\
\text { pipe }\end{array}$ \\
\hline $\begin{array}{c}\text { Stainless } \\
\text { steel plate } \\
\text { thickness } \\
0.03 \mathrm{~m} \\
\text { Density } \\
300 \\
\text { fin } / \mathrm{m}\end{array}$ & $\begin{array}{c}\text { In-line } \\
\mathrm{S}_{\mathrm{T}}=0.0508 \\
\mathrm{~mm} \\
\mathrm{~S}_{\mathrm{L}}=0.04 / \mathrm{N}_{\mathrm{L}} \\
\mathrm{mm}\end{array}$ & $\begin{array}{l}\mathrm{N}_{\mathrm{L}}=? \\
\mathrm{~N}_{\mathrm{T}}=8\end{array}$ & $\mathrm{~N}_{\text {total }}=\mathrm{N}_{\mathrm{T}} \times \mathrm{N}_{\mathrm{L}}$ & $\begin{array}{l}\text { Stainless } \\
\text { steel } \\
\text { Ammonia }\end{array}$ & $\begin{array}{c}0.4(\text { Length }) \times \\
0.4(\text { Width }) \times \\
0.8366(\text { Height })\end{array}$ & $\begin{array}{c}1.6732 \\
\text { (Length) } \\
\text { Internal } \\
\text { diameter } \\
0.0395 \mathrm{~m} \\
\text { Outside } \\
\text { diameter } \\
0.042 \mathrm{~m}\end{array}$ \\
\hline
\end{tabular}

Table1. Specifications of THE

\subsection{Calculation of Heat Transfer limits}

Optimum number of tube in length is 4 , the limits are calculated.

Table2. Value Heat transfer limits $\left(N_{l}=4\right)$

\begin{tabular}{|l|c|}
\hline Heat transfer limits & Value (Watt) \\
\hline sonic & $1.6 \times 10^{6}$ \\
\hline flooding & $1.36 \times 10^{4}$ \\
\hline boiling & $3.83 \times 10^{4}$ \\
\hline the input heat & $7.3 \times 10^{3}$ \\
\hline
\end{tabular}

The input heat $\left(6.06 \times 10^{3} \mathrm{w}\right)$ is lower than of the heat transfer limits, the thermosyphon operates without any problem. 


$$
\mathrm{Q}_{\text {in }}=m \cdot \Delta T_{h} \cdot C_{p, h}
$$

\subsection{Optimum Effectiveness}

By solving equations 1 to 21 , we can find the heat transfer efficiency factor $(\varepsilon)$. Figure (3) show that the changes coefficient of performance relative to the number of tube rows.

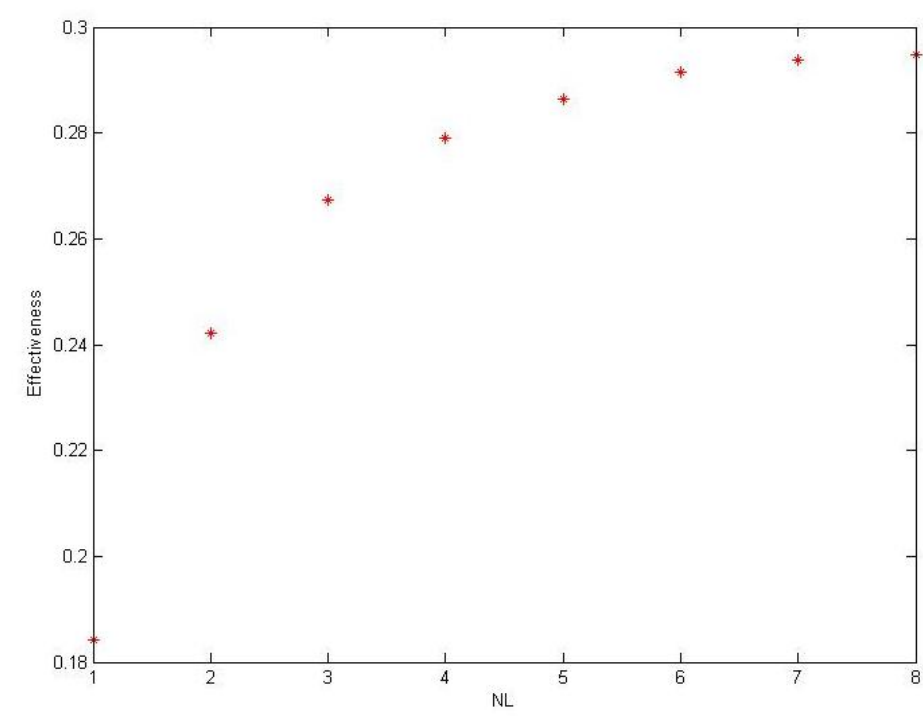

Fig 3: Effectiveness respect to number of row of bundle tube

\subsection{Savings in energy consumption before/after targeted subsidies plan}

The amount of saving in energy consumption is shown that in figure (4). With the implementation of targeted subsidies plan, Four times the savings can be achieved.

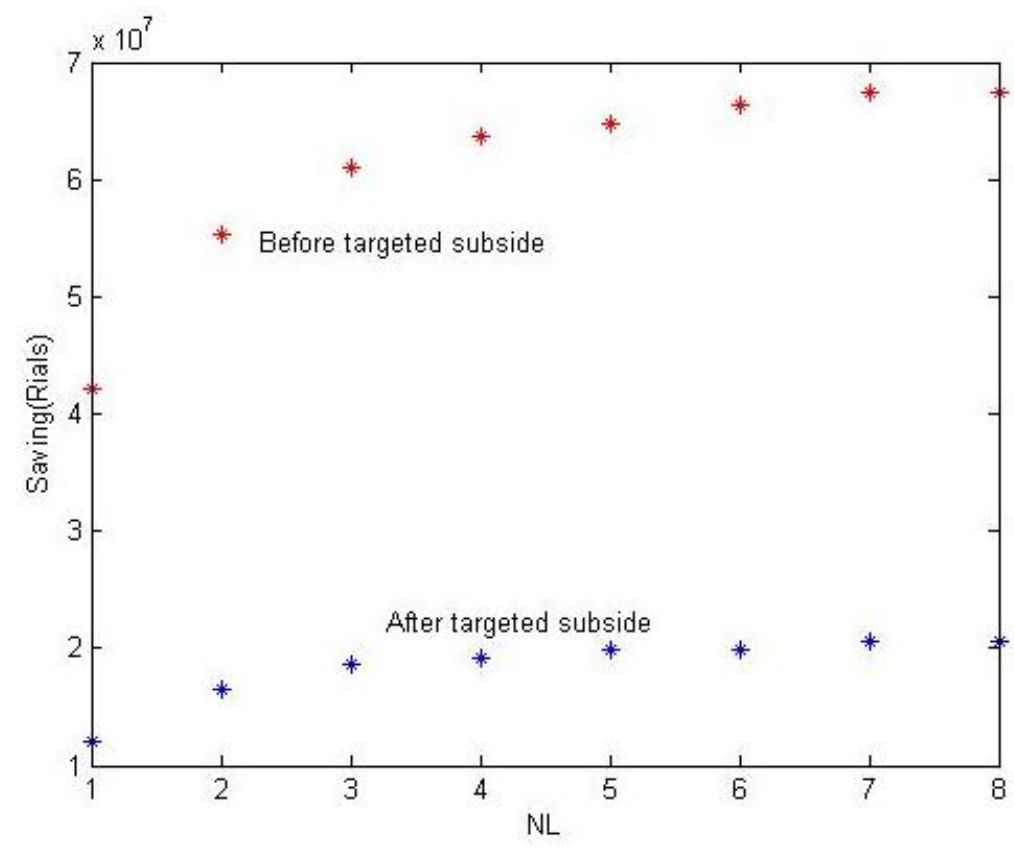

Fig 4: Savings in energy consumption for 9 month to number of row of bundle tube 


\subsection{Gasoil consumption}

In order to examine the energy savings with such a system let us consider a hypothetical unit. Figure (5) show that the effect of row of the tube on gas oil consumption.

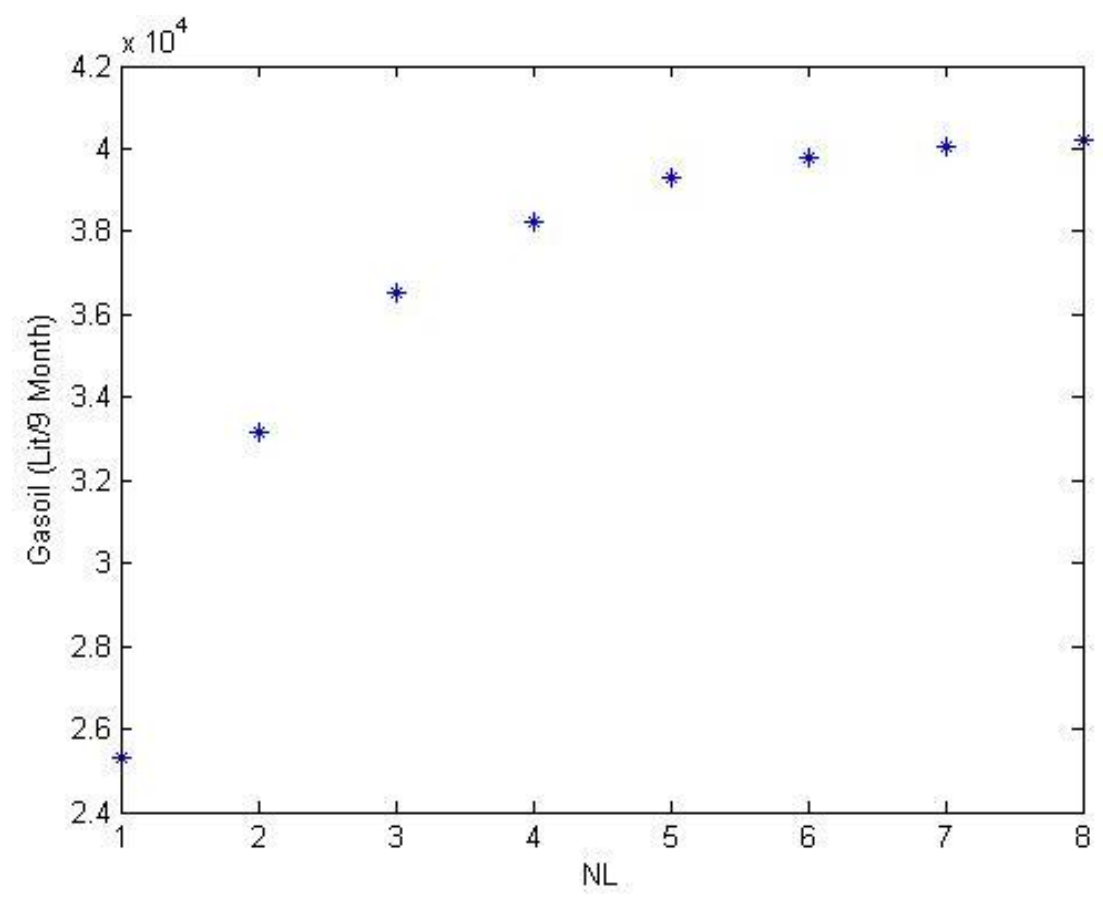

Fig 5: Gasoil consumption respect to row of tub

\subsection{Economic Assessment}

The cost of thermosyphon exchanger with the dimensions demonstrated in table (1) is $10,000,000$ Rial. For a farm with capacity of 10,000 chickens, 10 pieces of this pipe is normally used. Consequently, the total cost for this farm gets $100,000,000$ Rial. Noting that lifetime of the pipe is estimated about 10 years, a time of 2 years is sufficient to return the investment.

\section{Conclusions}

An air-to-air THE was modeled for energy recovery from the outlet stream of a hypothetical plant in the heating/cooling season. Also, the effect of row of pipe on heat transfer characteristics of a THE under normal operating conditions was investigated theoretically. The following conclusions were drawn from the present study:

1. Optimum number of tube in length is 4 .

2. with implementation of targeted subsides plan, saving in gas oil consumption is very considerable.

3. Surveys show that using thermosyphon exchangers in energy recycling systems of farms is extremely economic.

\section{Nomenclature}

C heat capacity of fluid

$\mathrm{C}_{\mathrm{h}} \quad$ heat capacity of hot fluid

Subscribes

$\mathrm{C}_{\mathrm{c}} \quad$ heat capacity of cold fluid

c condenser

e evaporator 
D inside diameter of heat pipe

L length of section

$\mathrm{m}$ mass flow rate of fluid in duct

$\mathrm{N}$ number of rows of tubes

Q heat transfer flux

$\mathrm{R}$ thermal resistance

$\mathrm{S}_{\mathrm{L}} \quad$ longitudinal tube pitch

$\mathrm{S}_{\mathrm{T}} \quad$ transverse tube pitch

$\mathrm{T}_{\mathrm{h}, \mathrm{i}} \quad$ temperature of flow, inlet of THE

$\mathrm{T}_{\mathrm{h} \text {,out }}$ temperature of flow, outlet of THE

$\mathrm{U}$ heat transfer coefficient

$\mathrm{U}_{\mathrm{t}} \quad$ total Heat transfer coefficient

Bo Bond number

$\mathrm{Q}_{c, 90}$ heat transfer rate limits at vertical state

$\mathrm{Q}_{\mathrm{c}, \infty} \quad$ critical heat transfer for pool boiling

$Q_{\text {in }} \quad$ input heat transfer into the evaporator

$\mathrm{T}_{\mathrm{V}} \quad$ vapor temperature

$\mathrm{h}_{\mathrm{fg}} \quad$ latent heat of vaporization

$\mathrm{A}_{\text {cross }}$ cross section area of pipe

$A_{v} \quad$ cross section area of vapor

\author{
f fin, fouling \\ i inside \\ o outside, overall \\ $\mathrm{p}$ pipe \\ w wick
}

\section{Greek letters}

$\eta$ fin effectiveness

$\rho$ density of fluid

$\varepsilon$ effectiveness

$\sigma$ surface tension

$\gamma$ specific heat ratio of air

$\Psi$ filling ratio

\section{References}

[1] S. W. Chi, "Heat Pipe Theory and Practice", McGraw Hill, New York (1976).

[2] M.R. Sarmasti Emami, "Energy Recovery in Poultry Plants by Heat Pipe Heat Exchangers", the 6th International Chemical Engineering Congress and Exhibition, 16-20 November, 2009, Kish, Iran.

[3] M.R. Sarmasti Emami, S.H. Noie, R. Shokri, "Simulation and economical investigation of application of heat pipe heat exchanger in air condition systems", $10^{\text {th }}$ National conference of Chemical Engineering, 2005, Zahedan, Iran.

[4] www.worldwatch.org

[5] J.O. Tan, C.Y. Liu, Predicting the Performance of a Heat Pipe Heat Exchanger using the Effectiveness NTU Method, Int. J. Heat Fluid Flow, 11(4), p.376 (1990).

[6] B.J. Haung, J.T. Tsuei, A Method of Analysis for Heat Pipe Heat Exchangers, Int. J. Heat Mass Transfer, 28(3), p. 553(1985).

[7] A. Faghri, "Heat pipe Science and Technology", Taylor \& Francis, USA, (1995).

[8] F.P. Incropera, D.P. DeWitt, "Fundamentals of Heat and Mass Transfer", 5th ed., John Wiley and Sons, New York, p.640 (2002).

[9] E. Azad, F. Geoola, A Design Procedure for Gravity-Assisted Heat Pipe Heat Exchanger, Heat Recovery

System, Elsevier Science, p. 101 (1984)

[10] Dunn, P. D., and Reay, D. A., Heat pipes, $3^{\text {rd }}$ ed., Pergamon Press, Oxford, U.K., 1994.

[11] A. Faghri, Heat pipe science and Technology, Taylor \& Francis, Washington, D.C., 1995.

[12] Z. R. Gorbis, and G.A. Savchenkov, Low Temperature Tow-phase Closed Thermosyphon Investigation, proc. 2nd International Heat pipe Conf. Bologna, Italy, pp.3745, 1967.

[13] M. Shiraishi, M. Yoneya, and A. Yabe, Visual study of operating limit in the Tow-Phase closed thermosyphone, proc. $5^{\text {th }}$ international Heat Pipe Conf., 14-17 May, Tsukuba, Japan, pp. 11-17, 1984. 